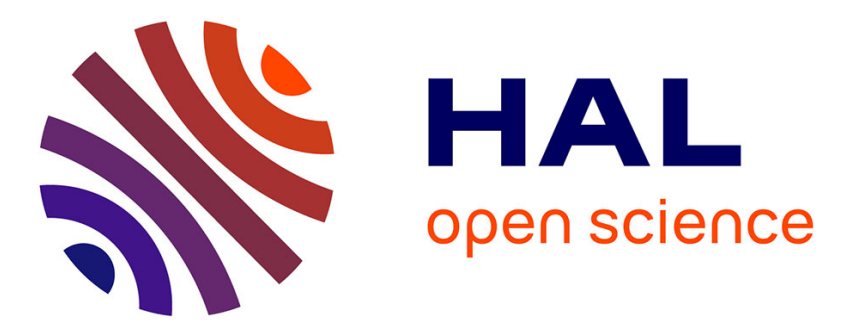

\title{
Tax Rate Variability and Public Spending as Sources of Indeterminacy
}

\author{
Teresa Lloyd-Braga, Leonor Modesto, Thomas Seegmuller
}

\section{To cite this version:}

Teresa Lloyd-Braga, Leonor Modesto, Thomas Seegmuller. Tax Rate Variability and Public Spending as Sources of Indeterminacy. Journal of Public Economic Theory, 2008, 10 (3), pp.399-421. 10.1111/j.1467-9779.2008.00369.x . halshs-00194395

\section{HAL Id: halshs-00194395 \\ https://shs.hal.science/halshs-00194395}

Submitted on 6 Dec 2007

HAL is a multi-disciplinary open access archive for the deposit and dissemination of scientific research documents, whether they are published or not. The documents may come from teaching and research institutions in France or abroad, or from public or private research centers.
L'archive ouverte pluridisciplinaire HAL, est destinée au dépôt et à la diffusion de documents scientifiques de niveau recherche, publiés ou non, émanant des établissements d'enseignement et de recherche français ou étrangers, des laboratoires publics ou privés. 


\title{
Tax Rate Variability and Public Spending as Sources of Indeterminacy*
}

\author{
Teresa Lloyd-Braga ${ }^{1}$, Leonor Modesto ${ }^{2 \dagger}$ and Thomas Seegmuller ${ }^{3}$ \\ ${ }^{1}$ Universidade Católica Portuguesa (UCP-FCEE) and CEPR \\ ${ }^{2}$ Universidade Católica Portuguesa (UCP-FCEE) and IZA \\ ${ }^{3} \mathrm{CES}$ and CNRS
}

April 3, 2007

\begin{abstract}
We consider a constant returns to scale, one sector economy with segmented asset markets of the Woodford (1986) type. We analyze the role of public spending, financed by labor income and consumption taxation, on the emergence of indeterminacy. We find that what is relevant for indeterminacy is the variability of the distortion introduced by government intervention. We further discuss the results in terms of the level of the tax rate, its variability with respect to the tax base and the degree of externalities in preferences due to the existence of a public good. We show that the degree of public spending externalities affects the combinations between the tax rate and its variability under which indeterminacy occurs. Moreover, in contrast to previous results, we find that consumption taxes can lead to local indeterminacy when asset markets are segmented.

Keywords: Indeterminacy, public spending, taxation, segmented asset markets.
\end{abstract}

JEL Classification: E32, E63, H23.

${ }^{*}$ Financial support from FCT-POCI/EGE/58650/2004, from GRICES/EGIDE, from CRUP/CPU and "Agence Nationale de la Recherche" (ANR-05-BLAN-0347-01) is gratefully acknowledged.

${ }^{\dagger}$ Corresponding Author: correspondence should be sent to Leonor Modesto, Universidade Católica Portuguesa, FCEE, Palma de Cima, 1649-023 Lisboa, Portugal. e-mail: lrm@fcee.ucp.pt. 


\section{Introduction}

The effects of government spending and taxes on income distribution, economic growth and welfare have been thoroughly discussed in the literature. More recently some papers have also stressed that fiscal policy may create indeterminacy, and thereby have destabilizing effects on the economy by triggering cycles driven by self-fulfilling volatile expectations, i.e. sunspots. The pioneer work of Schmitt-Grohé and Uribe (1997) shows that, in a Ramsey model with a pre-set level of government expenditures, when the labor income tax is determined by a balanced budget rule, the economy can exhibit an indeterminate steady state and a continuum of stationary sunspot equilibria. Pintus (2003) and Gokan (2006), considering the same fiscal policy rule, show that similar results are obtained in a segmented asset market economy of the Woodford (1986) type.

In this paper we extend this analysis, studying the role of public spending financed by labor income and consumption taxation on the emergence of indeterminacy, within a segmented asset markets economy of the Woodford (1986) type, for a wider class of fiscal policy rules.

It is well known that constant income tax rates can not be per se a source of local indeterminacy in a Ramsey model. ${ }^{1}$ The same happens in a segmented asset market economy as proved below. Therefore, we focus on variable tax rates, i.e. tax rates that vary (negatively or positively) with the tax base, while government spending adjusts in order to balance the budget. The tax rate rule considered is characterized by two parameters: the level of the tax rate and its variability with respect to the tax base. ${ }^{2}$ Our fiscal policy rule covers as particular cases the case of a constant flow of public expenditures, as considered in Schmitt-Grohé and Uribe (1997), Pintus (2003), Gokan (2006) and Giannitsarou (2007), and also the case of a constant tax rate as in Guo and Harrison (2004).

For some time, economists have been arguing that public goods and infrastructures may influence the utility of consumption. ${ }^{3}$ More recently, this idea has been exploited in works on indeterminacy and endogenous cycles.

\footnotetext{
${ }^{1}$ See Schmitt-Grohé and Uribe (1997) and Guo and Harrison (2004).

${ }^{2}$ The functional form considered for the tax rate is similar to the one used by Guo and Lansing (1998) in a Ramsey framework, although the tax bases are different. Dromel and Pintus (2004) also allow for tax rate variability but they restrict their analysis to the case of weak progressivity.

${ }^{3}$ For a seminal contribution, see Barro (1981).
} 
See for example Seegmuller (2003) and Utaka (2003) in a overlapping generations framework and Cazzavillan (1996), Zhang (2000), Fernandez et al. (2004) and Guo and Harrison (2006) in a Ramsey model. ${ }^{4}$ In this paper, we also introduce the possibility of positive government spending externalities in preferences. We assume that consumers derive utility from effective consumption, a composite good that combines private consumption and public expenditures. More precisely, we consider that private consumption and government services are non-separable and Edgeworth complements, following $\mathrm{Ni}$ (1995) who provides empirical support for these assumptions. ${ }^{5}$

A novel feature of our work is that we study how the degree of government spending externalities affects the combinations between the tax rate and its variability under which indeterminacy occurs, in a Woodford (1986) framework. For example, we find that in the absence of government spending externalities, for a given elasticity of the labor tax rate with respect to the tax base, a sufficiently low tax rate ensures determinacy. However, this is no longer true for higher values of public spending externalities. Also, with constant labor income tax rates, indeterminacy becomes possible when public spending externalities on preferences are sufficiently strong. Therefore, our results show that taking into account the degree of government spending externalities is crucial in order to correctly evaluate the dynamic implications of different fiscal policy rules.

Another novel feature of our work is that we study the effects of consumption taxation on indeterminacy in a segmented asset markets economy. Giannitsarou (2007), using a Ramsey model without public spending externalities, addressed only the case where a fixed stream of government spending is financed by consumption taxes, and found that indeterminacy was not possible in this case. Here, we consider a more general fiscal policy rule that encompasses the one analyzed in Giannitsarou (2007). We find that, in a segmented asset markets framework, indeterminacy is possible with a consumption tax rate that responds negatively to the tax base. In particular, in the case of the fiscal policy rule analyzed in Giannitsarou (2007) indeterminacy

\footnotetext{
${ }^{4}$ Note, however, that in all these papers simpler fiscal policy rules are considered: a constant tax rate and/or a constant stream of government expenditures.

${ }^{5}$ There is an ongoing debate in the literature discussing whether private consumption and government services are Edgeworth complements or substitutes. However, the conclusions from this empirical literature are mixed, not providing a clear answer to this question. See for example Karras (1994), Ni (1995), Evans and Karras (1996) and Amano and Wirjanto (1998).
} 
may emerge in our framework, even without public spending externalities on preferences. This shows that taxes have different effects on indeterminacy in segmented asset markets and Ramsey models. Being aware of the markets distortions (e.g. financial imperfections) existing in the pre-intervention situation is therefore also crucial to address correctly the dynamic implications of fiscal policy rules.

The rest of the paper is organized as follows. In the next section, we present the model used, that extends the Woodford (1986) framework to allow for public spending, which may affect preferences and is financed by labor and consumption taxes. We obtain the perfect foresight equilibrium and prove the existence and uniqueness of the steady state. In section 3 , we present and discuss in detail the indeterminacy results, providing an economic intuition and a numerical example. Finally, in the last section, we make some concluding remarks. Proofs are presented in the Appendix.

\section{The Model}

The model used is an extension of the Woodford (1986) framework that allows for public spending financed by taxation. We consider a perfectly competitive monetary economy with discrete time $t=1,2, \ldots, \infty$ and heterogeneous infinite lived agents. Indeed, following Woodford (1986), we assume that there are two types of agents, workers and capitalists. While workers and capitalists consume both the final good, only workers supply labor. Moreover, there is a financial market imperfection that prevents workers from borrowing against their wage income and workers are more impatient than capitalists, i.e. they discount the future more than the latter. So, in a neighborhood of a monetary steady state, capitalists hold the whole capital stock and no money, whereas workers save their wage earnings through money balances. The final good is produced by firms under a Cobb-Douglas technology characterized by constant returns to scale. Finally, we introduce government policy in this framework, and assume that public spending, that may affect workers utility, is financed by labor and/or consumption taxes. The detailed description of the model is provided below. 


\subsection{The Production Sector}

Both capital $k_{t}$ and labor $l_{t}$ are used to produce the final good, $y_{t}$, under a Cobb-Douglas technology with constant returns to scale:

$$
y_{t}=k_{t}^{s} l_{t}^{1-s}
$$

where $s \in(0,1)$ represents the capital share in total income. Producers maximize their profits. Since all markets are perfectly competitive, we obtain the following expressions for the real wage and the real interest rate:

$$
\begin{aligned}
\omega_{t} & =(1-s) k_{t}^{s} l_{t}^{-s} \equiv \omega\left(k_{t}, l_{t}\right) \\
\rho_{t} & =s k_{t}^{s-1} l_{t}^{1-s} \equiv \rho\left(k_{t}, l_{t}\right)
\end{aligned}
$$

\subsection{The Government}

The government chooses the tax policy and balances its budget at each period in time. Therefore, real public spending in goods and services in period $t$, $G_{t} \geq 0$ is given by:

$$
G_{t}=\tau_{l}\left(\omega_{t} l_{t}\right) \omega_{t} l_{t}+\tau_{c}\left(c_{t}\right) c_{t}
$$

where $\tau_{l}\left(\omega_{t} l_{t}\right)$ represents the labor tax rate determined as a function of aggregate labor income in the economy. Also $c_{t}=c_{t}^{w}+c_{t}^{c}$, where $c_{t}^{w}$ denotes consumption of workers in period $t, c_{t}^{c}$ denotes consumption of capitalists in period $t$ and $\tau_{c}\left(c_{t}\right)$ represents the consumption tax rate determined as a function of aggregate consumption. We assume that:

$$
\begin{aligned}
\tau_{l}\left(\omega_{t} l_{t}\right) & =\alpha_{l}\left(\frac{\omega_{t} l_{t}}{\omega l}\right)^{\phi_{l}} \\
\tau_{c}\left(c_{t}\right) & =\alpha_{c}\left(\frac{c_{t}}{c}\right)^{\phi_{c}}
\end{aligned}
$$

where $\omega l$ is the steady state value of the wage bill, and $c$ is the steady state level of total consumption. The parameter $0 \leq \alpha_{l}<1$ determines the level of the tax rate on labor income at the steady state. Similarly $\alpha_{c} \geq 0$ determines the level of the consumption tax rate at the steady state. The parameters $\phi_{j} \in \mathbb{R}$ with $j=l, c$ denote the elasticities of the tax rates with respect to the tax bases. When $\phi_{j}<0$ the tax rate decreases when the tax base 
expands, $\phi_{j}>0$ corresponds to the cases where the tax rate increases with the tax base, and for $\phi_{j}=0$ the tax rate is constant. The specification considered for the fiscal policy rule given by (4), (5) and (6) nests most of the cases considered in the literature. Indeed it nests the case considered in Schmitt-Grohé and Uribe (1997), Pintus (2003) and Gokan (2006) where a constant amount of public expenditures is financed by taxes on labor income, so that $\tau_{l}\left(\omega_{t} l_{t}\right)=G / \omega_{t} l_{t}$. Hence we recover their specification when $\phi_{l}=-1$, $\alpha_{l}=G / \omega l$ and $\alpha_{c}=0$. Moreover, we admit as a particular case Giannitsarou (2007) for $\alpha_{l}=0, \alpha_{c}=G / c$ and $\phi_{c}=-1$, which means that constant public expenditures are only financed by consumption taxes. ${ }^{6}$

\subsection{Workers}

We assume a continuum of identical workers of mass one. Preferences of each worker may be affected by public expenditures and are represented by the following utility function:

$$
\sum_{t=1}^{\infty} \lambda^{t-1}\left[U\left(\frac{G_{t}^{\eta} c_{t}^{w}}{B}\right)-\lambda V\left(l_{t}\right)\right]
$$

where $l_{t}$ is labor supply, $c_{t}^{w}$ is his consumption, and $\lambda \in(0,1)$ is the discount factor. Public spending externalities in preferences are given by $G^{\eta}$, where $\eta \geq 0$ represents the degree of these externalities, ${ }^{7}$ and we call $G_{t}^{\eta} c_{t}^{w}$ effective consumption. Moreover, we make the following assumptions on the utility functions $U$ and $V$ :

Assumption 1 The functions $U(x)$ and $V(l)$ are continuous for all $x \geq 0$ and $0 \leq l \leq \widetilde{l}$, where the labor endowment $\widetilde{l}>0$ may be finite or infinite. They are $\mathcal{C}^{n}$ for $x>0,0<l<\widetilde{l}$ and $n$ large enough, with $U^{\prime}(x)>0$, $U^{\prime \prime}(x) \leq 0, V^{\prime}(l)>0$ and $V^{\prime \prime}(l) \geq 0$. Moreover, $\lim _{l \rightarrow \vec{l}} V^{\prime}(l)=+\infty$ and $-x U^{\prime \prime}(x) / U^{\prime}(x)<1$.

\footnotetext{
${ }^{6}$ Note that if we had considered more general tax rates functions, instead of assuming an isoelastic specification as in (5) and (6), our indeterminacy results would not change, provided $\alpha_{j}$ and $\phi_{j}$ respectively denote the level of the tax rates and their elasticities with respect to the tax base evaluated at the steady state.

${ }^{7}$ Note that if we had considered a more general multiplicative externality function, our indeterminacy results would be identical, provided $\eta$ denotes the elasticity of this function evaluated at the steady state.
} 
Note that under Assumption 1, when $\eta>0, c_{t}^{w}$ and $G_{t}$ are Edgeworth complements $\left(\frac{\partial^{2} U(x)}{\partial c^{w} \partial G}>0\right) .^{8}$

In the following $m_{t+1}^{w}$ and $k_{t+1}^{w}$ denote respectively the money balances and the capital stock held by the representative worker at the end of period $t, \delta \in(0,1)$ is the depreciation rate of capital, $r_{t}$ the nominal interest rate, $w_{t}$ the nominal wage, and $p_{t}$ the price of the final good. At each period, a worker faces the two following constraints:

$p_{t} c_{t}^{w}\left(1+\tau_{c}\left(c_{t}\right)\right)+p_{t}\left(k_{t+1}^{w}-(1-\delta) k_{t}^{w}\right)+m_{t+1}^{w}=m_{t}^{w}+r_{t} k_{t}^{w}+\left(1-\tau_{l}\left(\omega_{t} l_{t}\right)\right) w_{t} l_{t}$

$$
p_{t} c_{t}^{w}\left(1+\tau_{c}\left(c_{t}\right)\right)+p_{t}\left(k_{t+1}^{w}-(1-\delta) k_{t}^{w}\right) \leq m_{t}^{w}+r_{t} k_{t}^{w}
$$

where (8) represents the budget constraint and (9) the liquidity constraint. The representative worker maximizes his utility function (7) under the constraints (8) and (9). Workers know the policy rule followed by the government. However, since there is a continuum of agents, each worker, being atomistic, does not take into account the influence of its actions on aggregate variables. This means that workers take $G_{t}, \tau_{c}\left(c_{t}\right)$ and $\tau_{l}\left(\omega_{t} l_{t}\right)$ as given when solving their maximization problem. The equilibria considered here are such that:

$$
\begin{gathered}
G_{t}^{\eta} U^{\prime}\left(\frac{G_{t}^{\eta} c_{t}^{w}}{B}\right)>\lambda G_{t+1}^{\eta} U^{\prime}\left(\frac{G_{t+1}^{\eta} c_{t+1}^{w}}{B}\right)\left[(1-\delta)+r_{t+1} / p_{t+1}\right] \\
(1-\delta) p_{t+1}+r_{t+1}>p_{t}
\end{gathered}
$$

Then, workers always choose to not hold capital and the finance constraint is binding. Therefore, we obtain the following equations:

$$
\begin{gathered}
u\left(\frac{G_{t+1}^{\eta} c_{t+1}^{w}}{B}\right)=v\left(l_{t}\right) \\
m_{t+1}^{w}=\left(1-\tau_{l}\left(\omega_{t} l_{t}\right)\right) w_{t} l_{t} \\
p_{t} c_{t}^{w}\left(1+\tau_{c}\left(c_{t}\right)\right)=m_{t}^{w}
\end{gathered}
$$

${ }^{8} \mathrm{Ni}(1995)$ provides empirical support for Edgeworth complementarity between private and public consumption. 
where $u(x)=x U^{\prime}(x)$ and $v(l)=l V^{\prime}(l)$. We can further notice that under Assumption 1, there exists a function $\gamma \equiv u^{-1} \circ v$, called the offer curve, such that $G_{t+1}^{\eta} c_{t+1}^{w} / B=\gamma\left(l_{t}\right)$ and $\varepsilon_{\gamma}(l) \equiv \gamma^{\prime}(l) l / \gamma(l) \geq 1$, i.e. consumption and labor are gross substitutes. ${ }^{9}$

\subsection{Capitalists}

Capitalists behave like a representative agent who maximizes his lifetime utility function:

$$
\sum_{t=1}^{\infty} \beta^{t} \ln c_{t}^{c}
$$

where $\beta \in(\lambda, 1)$ is his discount factor and $c_{t}^{c}$ his consumption. ${ }^{10}$ At period $t$, the representative agent faces the following budget constraint:

$$
p_{t} c_{t}^{c}\left(1+\tau_{c}\left(c_{t}\right)\right)+p_{t}\left(k_{t+1}^{c}-(1-\delta) k_{t}^{c}\right)+m_{t+1}^{c}=m_{t}^{c}+r_{t} k_{t}^{c}
$$

where $m_{t+1}^{c}$ and $k_{t+1}^{c}$ are respectively the money balances and the capital stock held at the end of period $t$ by capitalists. Since we focus on equilibria satisfying (11), capitalists do not hold money $\left(m_{t}^{c}=0\right)$ because it has a lower return than capital. We obtain then, the following optimal solution:

$$
\begin{aligned}
c_{t}^{c} & =\frac{(1-\beta) R_{t} k_{t}}{1+\tau_{c}\left(c_{t}\right)} \\
k_{t+1} & =\beta R_{t} k_{t}
\end{aligned}
$$

where $R_{t} \equiv 1-\delta+r_{t} / p_{t}$ is the real gross return on capital. ${ }^{11}$

\subsection{Equilibrium}

Equilibrium on labor and capital markets requires $\omega_{t}=w_{t} / p_{t}, \rho_{t}=r_{t} / p_{t}$. Considering that $m>0$ is the constant money supply, and using (13) and

\footnotetext{
${ }^{9}$ Gross substitutability means that consumption is increasing in labor along the offer curve, i.e. $\frac{V^{\prime}(l)+l V^{\prime \prime}(l)}{\left[U^{\prime}(x)+x U^{\prime \prime}(x)\right] G^{\eta} / B}>0$. In our case this is verified since $V(l)$ is increasing and convex, and the degree of concavity of $U(x)$ belongs to $(0,1)$.

${ }^{10}$ We do not introduce public expenditure externalities into capitalists' preferences because, since they have a log-linear utility function, such externalities would not affect the dynamics.

${ }^{11}$ The superscript on $k_{t}^{c}$ is dropped because as we have seen before, workers do not hold capital.
} 
(14), equilibrium in the money market at each period implies the following:

$$
m / p_{t}=\left(1+\tau_{c}\left(c_{t}\right)\right) c_{t}^{w}=\left(1-\tau_{l}\left(\omega_{t} l_{t}\right)\right) \omega_{t} l_{t}
$$

Therefore, in equilibrium, from (12) and (18) we obtain:

$$
\begin{gathered}
\omega_{t+1} l_{t+1} \varphi\left(k_{t+1}, l_{t+1}\right) / B=\gamma\left(l_{t}\right) \\
k_{t+1}=\beta\left[\rho_{t}+1-\delta\right] k_{t}
\end{gathered}
$$

with

$$
\varphi\left(k_{t+1}, l_{t+1}\right)=G_{t+1}^{\eta} \frac{1-\tau_{l}\left(\omega_{t+1} l_{t+1}\right)}{1+\tau_{c}\left(c_{t+1}\right)}
$$

where $\omega_{t}$ and $\rho_{t}$ satisfy respectively $(2)$ and $(3), G_{t}, \tau_{l}\left(\omega_{t} l_{t}\right)$ and $\tau_{c}\left(c_{t}\right)$ are given respectively by (4), (5) and (6), and $c_{t}=c_{t}^{w}+c_{t}^{c}$, where $c_{t}^{w}$ and $c_{t}^{c}$ satisfy respectively (19) and (17).

Equations (20) and (21) determine the dynamics of this economy through a two-dimensional dynamic system with one predetermined variable, the capital stock $k_{t}$. Indeed, the perfect foresight intertemporal equilibrium of this economy is a sequence $\left(k_{t}, l_{t}\right) \in \mathbb{R}_{++} \times(0, \tilde{l}), t=1,2, \ldots \infty$ that, for a given $k_{1}>0$, solves the two-dimensional dynamic system (20) and (21). Note that while $k_{t}$ is a variable determined by past actions, the value of $l_{t}$, on the contrary, is affected by expectations of future events.

The function $\varphi\left(k_{t}, l_{t}\right)$ denotes the distortion introduced by government intervention in this economy. Remark that the distortion function $\varphi$ can be decomposed in two factors. The distortion due to government spending externalities is given by $G_{t}^{\eta}$, while $\left(1-\tau_{l}\left(\omega_{t} l_{t}\right)\right) /\left(1+\tau_{c}\left(c_{t}\right)\right)$ represents the gap between real wages relevant to consumers and producers, due to taxation (the tax wedge). For further reference we define $\varepsilon_{\varphi z}(k, l) \equiv \frac{\partial \varphi(k, l)}{\partial z} \frac{z}{\varphi(k, l)} \in \mathbb{R}$, with $z \in\{k, l\}$.

Finally, note that in the absence of government intervention, i.e. when $\varphi\left(k_{t}, l_{t}\right)=1$, so that $\varepsilon_{\varphi l}(k, l)=\varepsilon_{\varphi k}(k, l)=0$ for any $(k, l) \in \mathbb{R}_{++} \times(0, \tilde{l})$, (20) and (21) describe the dynamics of the standard Woodford (1986) model studied in Grandmont et al. (1998).

\subsection{Steady State Analysis}

In this section, we establish conditions for the existence of a unique steady state $(k, l)$ of the dynamic system (20) and (21). 
Proposition 1 Existence and uniqueness of the steady state:

Defining $H(l) \equiv l \varphi\left(a^{*} l, l\right) / \gamma(l), a^{*}=(s \beta / \theta)^{1 /(1-s)}$ and $\theta \equiv 1-\beta(1-\delta) \in$ $(0,1)$, and assuming that $(1-s)\left(a^{*}\right)^{s} \min \left\{\lim _{l \rightarrow 0} H(l), \lim _{l \rightarrow \mathfrak{l}} H(l)\right\}<B<$ $(1-s)\left(a^{*}\right)^{s} \max \left\{\lim _{l \rightarrow 0} H(l), \lim _{l \rightarrow \widetilde{l}} H(l)\right\}$, the dynamic system (20)-(21) has a unique steady state $(k, l)$ if one of the two following conditions is satisfied:

1. Either $1+\varepsilon_{\varphi k}\left(a^{*} l, l\right)+\varepsilon_{\varphi l}\left(a^{*} l, l\right)>\varepsilon_{\gamma}(l)$ for $l \in(0, \tilde{l})$

2. or $1+\varepsilon_{\varphi k}\left(a^{*} l, l\right)+\varepsilon_{\varphi l}\left(a^{*} l, l\right)<\varepsilon_{\gamma}(l)$ for $l \in(0, \tilde{l})$

Proof. See the Appendix.

\section{Indeterminacy}

Assuming that Proposition 1 is verified, we now study the local indeterminacy of the steady state. We summarize our results in Proposition 2 below, where $\varepsilon_{\gamma} \geq 1, \varepsilon_{\varphi k}$ and $\varepsilon_{\varphi l}$ denote respectively the elasticities $\varepsilon_{\gamma}(l), \varepsilon_{\varphi k}(k, l)$ and $\varepsilon_{\varphi l}(k, l)$ evaluated at the steady state.

\section{Proposition 2 Indeterminacy}

The steady state will be indeterminate if and only if:

(i) either $\varepsilon_{\varphi l}>\max \left\{\varepsilon_{\varphi l}^{T}, \varepsilon_{\varphi l}^{H}, \varepsilon_{\varphi l}^{F}\right\}$;

(ii) or $\varepsilon_{\varphi l}<\min \left\{s-1, \varepsilon_{\varphi l}^{T}, \varepsilon_{\varphi l}^{F}\right\}$;

where:

$\varepsilon_{\varphi l}^{T}=-\varepsilon_{\varphi k}+\left(\varepsilon_{\gamma}-1\right)$

$\varepsilon_{\varphi l}^{H}=[s-\theta(1-s)]+[1-\theta(1-s)]\left(\varepsilon_{\gamma}-1\right)$

$\varepsilon_{\varphi l}^{F}=-\frac{\left[4-2 s-\theta(1-s)\left(2+\varepsilon_{\varphi k}\right)\right]}{2-\theta(1-s)}-\left(\varepsilon_{\gamma}-1\right)$.

Proof. See the Appendix.

Note that, in this framework, it is not the level of the distortion introduced by government intervention per se that is responsible for the emergence of indeterminacy, but its variability $\left(\varepsilon_{\varphi k} \neq 0, \varepsilon_{\varphi l} \neq 0\right)$. Indeed when $\varepsilon_{\varphi k}=$ $\varepsilon_{\varphi l}=0$, the case studied in Grandmont et al. (1998), we can see from Proposition 2 that the steady state can never be indeterminate. For instance, when $\varepsilon_{\varphi k}=0$, from $(i)$ of Proposition 2 we have that $\varepsilon_{\varphi l}>\left(\varepsilon_{\gamma}-1\right) \geq 0$ 
is a necessary condition for indeterminacy, and from $(i i)$ it is necessary that $\varepsilon_{\varphi l}<s-1<0$ for indeterminacy to emerge. Moreover, when $\theta$ is small, i.e. $\theta(1-s)<s$ as usually assumed in the Woodford (1986) framework, ${ }^{12} \varepsilon_{\varphi l}^{H}$ is positive, so that condition $(i)$ requires a positive value for $\varepsilon_{\varphi l}$ bounded away from zero. Since from condition (ii) $\varepsilon_{\varphi l}$ must take a negative value bounded away from zero $\left(\varepsilon_{\varphi l}<s-1<0\right)$ we conclude that indeterminacy is not possible for arbitrarily small values of $\varepsilon_{\varphi k}$ and $\varepsilon_{\varphi l}$ when $\theta$ is small.

For future reference let us define

$$
\epsilon_{\varphi} \equiv \varepsilon_{\varphi k}+\varepsilon_{\varphi l}
$$

As we shall see, for the class of policy rules here considered, the parameter $\epsilon_{\varphi}$ summarizes the influence of the policy rule on the distortion variability.

\subsection{Indeterminacy with Labor Taxation}

In this section we discuss in detail the case where only labor taxation is used to finance public spending, i.e. where $\alpha_{c}=0$ so that $\tau_{c}\left(c_{t}\right)=0$, (see (6)). In this case (4) and (22) become

$$
\begin{gathered}
G_{t+1}=\tau_{l}\left(\omega_{t+1} l_{t+1}\right) \omega_{t+1} l_{t+1} \\
\varphi\left(k_{t+1}, l_{t+1}\right)=G_{t+1}^{\eta}\left(1-\tau_{l}\left(\omega_{t+1} l_{t+1}\right)\right)
\end{gathered}
$$

where $\tau_{l}(\omega l)$ satisfies (5). Therefore we obtain

$$
\begin{aligned}
\varepsilon_{\varphi l} & =\left[\eta\left(1+\phi_{l}\right)-\phi_{l} \frac{\alpha_{l}}{1-\alpha_{l}}\right](1-s) \\
\varepsilon_{\varphi k} & =\left[\eta\left(1+\phi_{l}\right)-\phi_{l} \frac{\alpha_{l}}{1-\alpha_{l}}\right] s
\end{aligned}
$$

so that $\epsilon_{\varphi}($ see $(23))$ is given by: ${ }^{13}$

$$
\epsilon_{\varphi}=\left[\eta\left(1+\phi_{l}\right)-\phi_{l} \frac{\alpha_{l}}{1-\alpha_{l}}\right]
$$

\footnotetext{
${ }^{12}$ Note that this assumption is frequently used in the literature (see Cazzavillan et al. (1998)) and covers most commonly used parameterizations for the Woodford model. Indeed most monthly parameterizations set $\theta$ close to 0.0123 .

${ }^{13}$ Note that here $\epsilon_{\varphi}$ represents also the elasticity of the function $\varphi$ with respect to the tax base (the wage bill), evaluated at the steady state.
} 
From Proposition 2 and (26)-(27), we can see that government policy influences the occurrence of indeterminacy through the parameters $\eta, \phi_{l}$ and $\alpha_{l}$ : $\eta\left(1+\phi_{l}\right)$ is associated with the variability of the public spending externality on preferences, ${ }^{14}$ while $\phi_{l} \frac{\alpha_{l}}{1-\alpha_{l}}$ is associated with the variability of the tax wedge. These parameters only influence $\varepsilon_{\varphi l}$ and $\varepsilon_{\varphi k}$ through a single factor $\epsilon_{\varphi}$. Hence $\epsilon_{\varphi}$ summarizes the variability of the distortion introduced by fiscal policy.

Using Proposition 2, we now derive the indeterminacy conditions corresponding to the labor taxation case. In order to make the analysis comparable to the existing literature we set $\epsilon_{\gamma}=1 .^{15}$ We summarize our results in Proposition 3 below.

Proposition 3 Indeterminacy under labor taxation and public expenditures externalities:

Assuming that $\theta(1-s)<s$ and $\epsilon_{\gamma}=1$, the steady state will be indeterminate if and only if $\epsilon_{\varphi}>\frac{[s-\theta(1-s)]}{(1-s)}$ or $\epsilon_{\varphi}<\frac{-2[2-s-\theta(1-s)]}{(2-\theta)(1-s)}$, i.e. iff:

(i) for $\alpha_{l}<\eta /(1+\eta)$ either $\phi_{l}>\phi_{l}^{H}$ or $\phi_{l}<\phi_{l}^{F}$

(ii) for $\alpha_{l}>\eta /(1+\eta)$ either $\phi_{l}<\phi_{l}^{H}$ or $\phi_{l}>\phi_{l}^{F}$

where:

$$
\begin{aligned}
\phi_{l}^{H} & =\frac{\left(1-\alpha_{l}\right)[s-\theta(1-s)-\eta(1-s)]}{(1-s)\left[\eta-\alpha_{l}(1+\eta)\right]} \\
\phi_{l}^{F} & =\frac{-\left(1-\alpha_{l}\right)\{2[2-s-\theta(1-s)]+\eta(1-s)(2-\theta)\}}{(1-s)(2-\theta)\left[\eta-\alpha_{l}(1+\eta)\right]}
\end{aligned}
$$

Proof. See the Appendix.

From Proposition 3 we can see that indeterminacy is more likely the higher the (absolute) value of $\epsilon_{\varphi}$, i.e. the stronger the variability of the distortion.

\subsubsection{Economic Intuition}

In our framework the variability of the distortion introduced by government intervention is the mechanism responsible for indeterminacy, which emerges

\footnotetext{
${ }^{14}$ When $\phi_{l}=-1$ the variability of the public spending externality disappears, because this corresponds to the case where $G$ is constant.

${ }^{15}$ Note that this corresponds to the case of an infinitely elastic labor supply curve.
} 
if this variability is sufficiently strong. Indeed, as discussed before, when $\varepsilon_{\varphi l}=\varepsilon_{\varphi k}=0$, so that $\epsilon_{\varphi}=0$, we recover the case considered in Grandmont et al. (1998), where the steady state is never indeterminate in the CobbDouglas case. In order to understand why, consider the following intuitive argument that, since local indeterminacy means that local equilibrium trajectories converge to the steady state, is based on the existence of a mechanism able to bring back to the steady state any deviating trajectory. Consider for instance that in period $t$, starting from the steady state, there is an instantaneous increase in the capital stock $k_{t}$. This implies an increase in $k_{t+1}$ (see (21)), and therefore in the future wage bill. In the absence of public spending financed by labor taxation this increase in the future wage bill must be sustained by an increase in current employment, see (20), which in turn implies an increase in the current interest rate (see (3)), that reinforces the initial increase in $k_{t+1}$. This in turn implies a decrease in the rental rate of capital at $t+1$. In order to obtain a reversal in the trajectory a sufficiently important decrease in the rental rate of capital at $t+1$ should be observed, so that $k_{t+2}$ decreases. However, in the Cobb-Douglas case this can never happen so that indeterminacy never emerges.

Consider now the case where $\epsilon_{\varphi}>0$, i.e. where we have tax rates that respond negatively to the tax base $(\phi<0)$ and/or public spending externalities $(\eta>0)$. See equation (28). Now, the increase in future capital implies an increase in the future wage and in the distortion function $\varphi\left(k_{t+1}, l_{t+1}\right)$ that, as before, must be sustained by an increase in current labor (see (20)). This last effect triggers all the events described above, implying a decrease in the rental rate of capital at $t+1$. However now, if $\epsilon_{\varphi}$ is sufficiently big, the observed increase in current employment is consistent with a decrease in future labor $l_{t+1}($ see $(20))$. This implies a sufficiently fall in $r_{t+1}$, that reverses the trajectory of capital.

Assume now that $\epsilon_{\varphi}<0$, i.e. taxes vary positively with the tax base $(\phi>0)$. Then, if $\epsilon_{\varphi}$ is sufficiently big in absolute value, the increase in the future wage bill may, in contrast to what happened in the two previous cases, lead to a decrease in current employment. See equation (20). This last effect has a negative impact on the current interest rate (see (3)), which reduces $k_{t+1}$ restoring the path to equilibrium.

We can therefore understand why the emergence of indeterminacy requires sufficiently high (in absolute terms) values for $\epsilon_{\varphi}$, i.e. a sufficiently elastic response of the function $\varphi$ with respect to capital and labor. 


\subsubsection{Discussion of the Results}

In this section we discuss and compare our indeterminacy results with previous papers that have addressed related issues. To ease the discussion we have plotted, in figures 1 and $2, \phi_{l}^{H}$ and $\phi_{l}^{F}$ as functions of $0<\alpha_{l}<1$, for different values of $\eta \geq 0$, assuming that $\theta(1-s)<s$. The indeterminacy region is the shaded area.

(insert figure 1 here)

The case of $\eta=0$, where public spending does not affect workers' utility, falls into case (ii) of Proposition 3 and is depicted in the right-hand side (RHS) of figure 1 where $\alpha_{l}$ is always greater than $\eta /(1+\eta)=0$. We can see that, in this case, indeterminacy is not possible with a constant tax rate $\left(\phi_{l}=0\right) .{ }^{16}$ The same result was obtained in a Ramsey model by Schmitt-Grohé and Uribe (1997) and Guo and Harrison (2004). However, for any given level of $\alpha_{l}$, a sufficiently (positively or negatively) elastic tax rule implies the existence of indeterminacy. In this respect we differ from Guo and Lansing (1998) and Dromel and Pintus (2004), that find, respectively in the Benhabib and Farmer (1994) framework and in a Woodford model without government spending externalities, that determinacy is more likely when the tax schedule becomes more progressive. Note, however, that both Guo and Lansing (1998) and Dromel and Pintus (2004) consider that agents take into account how the tax rate affects their earnings. Therefore, they have to exclude parameter configurations where after tax income decreases with income. With our notation, this means that they do not consider the cases where $\epsilon_{\varphi}<-1$, i.e. $\phi_{l}>\left(1-\alpha_{l}\right) / \alpha_{l}$. On the contrary, in our case, since agents take the tax rate as given, these parameter configurations are possible, and indeterminacy occurs for $\phi_{l}>\phi_{l}^{F}>\left(1-\alpha_{l}\right) / \alpha_{l}$.

From the RHS of figure 1 we can also see that, when $\eta=0$, for a given level of $\phi_{l} \neq 0$, indeterminacy requires a sufficiently high level of $\alpha_{l}$. In particular, when a constant level of $G$ is assumed $\left(\phi_{l}=-1\right)$, local indeterminacy emerges when $\alpha_{l}>\alpha_{l}^{*}=[s-\theta(1-s)] /[1-\theta(1-s)]$. This result is in accordance with previous works considering labor taxation and no public expenditures externalities. See for instance Schmitt-Grohé and Uribe (1997), Pintus (2003) and Gokan (2006) who assume a constant level of $G$ and all

\footnotetext{
${ }^{16}$ Note that, when $\eta=0$, in the case of a constant tax rate we have $\varepsilon_{\varphi l}=\varepsilon_{\varphi k}=0$ (see (26) to (28)), so that, as shown before, indeterminacy is not possible.
} 
find that indeterminacy requires a lower bound for the tax rate. Note also that when $\phi_{l}=-1$, we obtain this same indeterminacy condition on $\alpha_{l}$ for any value of $\eta \geq 0$, because the effect of the public spending externality disappears when $G$ is constant. Guo and Harrison (2006) also find that, in the Schmitt-Grohé and Uribe (1997) framework $\left(\phi_{l}=-1\right)$, government spending externalities do not affect indeterminacy conditions.

We can therefore conclude that for a given value of $\phi_{l}$, a sufficiently low level of the tax rate stabilizes economic fluctuations, whereas for a given level of the tax rate, $\alpha_{l}$, tax schedules sufficiently elastic destabilize the economy. This means that there is a trade-off between the values of these two parameters, $\phi_{l}$, the tax response to the business cycle and $\alpha_{l}$, the level of tax rate, needed for determinacy: the higher the elasticity of the tax schedule, the lower the tax rate needed to ensure determinacy of the steady state.

When $\eta>0$ two different configurations are possible depending on whether $\eta \gtrless \eta^{*} \equiv[s-\theta(1-s)] /(1-s)$. In figure 1 we represent the case where $\eta<\eta^{*}$. We can see that, in this case, indeterminacy is still not possible with a constant tax rate $\left(\phi_{l}=0\right)$. However, for low values of $\alpha_{l}\left(\alpha_{l}<\eta /(1+\eta)\right)$, a new type of configuration, that reverses the trade-off between $\alpha_{l}$ and $\phi_{l}$ needed for determinacy, is obtained: the higher $\phi_{l}$ (in absolute value), the higher the value of $\alpha_{l}$ required for determinacy.

\section{(insert figure 2 here)}

Finally the case of higher public spending externalities, $\eta>\eta^{*}$, is represented in figure 2 . We can see that, in this case, indeterminacy prevails for $\phi_{l} \geq 0$ and $\alpha_{l}<\eta /(1+\eta)$, and for $\phi_{l} \leq 0$ and $\alpha_{l}>\eta /(1+\eta)$. In particular, and in contrast to what happened in the other two previous cases, indeterminacy is now always obtained with a constant tax rate $\left(\phi_{l}=0\right)$. Indeed, using Proposition 3 , we can easily prove that, when $\phi_{l}=0$, indeterminacy requires a minimum degree for public spending externalities in preferences, precisely $\eta>\eta^{*}$. Cazzavillan (1996) and Guo and Harrison (2006), in optimal growth models with public spending externalities on preferences and a constant tax rate, also find that a minimum bound for the elasticity of the public spending externalities is required for indeterminacy to emerge. For related findings in overlapping generations models, see Seegmuller (2003) and Utaka (2003). These results suggest that public expenditures externalities on preferences constitute an important channel for the emergence of indeterminacy.

The results here obtained show that fiscal policy rules may be responsible 
for indeterminacy, and thereby their design should take into account their possible destabilizing effects through this channel. This is an issue already emphasized in several other works, but our results further show that the way $\phi_{l}$ and $\alpha_{l}$ interact in order to create local indeterminacy strongly depends on the presence and strength of public spending externalities.

Finally, since indeterminacy is linked to expectations driven fluctuations, a relevant issue is to understand whether such fluctuations are costly from a welfare point of view. We know that in a constant returns to scale economy without externalities and/or government intervention, the concavity of utility makes volatile paths welfare inferior to stationary allocations (concavity effect). However, in the presence of productive externalities that imply increasing returns at the social level, Christiano and Harrison (1999) show that despite concavity in the utility function, increasing volatility may raise welfare for the representative agent. In their set-up, this happens because with increasing returns, "by bunching hard work, consumption can be increased on average without raising the average level of employment (bunching effect)." Then, if this last effect dominates, fluctuations can be welfare improving. In our set-up, things are more complicated because we have two types of agents. In the case of capitalists, only the concavity effect applies so that fluctuations are welfare decreasing. However, in the case of workers, a bunching effect can occur. In fact, if effective consumption $\left(G_{t}^{\eta} c_{t}^{w}\right)$ is convex in the tax base (i.e. in production) ${ }^{17}$ by bunching labor (capital) effective consumption can be increased on average without raising the average level of employment (capital). Since worker preferences are concave in effective consumption and leisure, if effective consumption is sufficiently convex with respect to labor income, the bunching effect dominates so that fluctuations can be welfare improving for workers. For example, in the limit case of $\epsilon_{\gamma}=1$, this happens for $\eta>0$ sufficiently high. However, since for capitalists fluctuations are always welfare costly, even if the worker bunching effect dominates, we cannot claim that fluctuations are welfare improving. On the contrary, if for workers the bunching effect is dominated by the concavity effect, fluctuations are welfare costly. In this last case, a fiscal policy that promotes indeterminacy should be avoided.

\footnotetext{
${ }^{17}$ Using (19) and (24), we can see that effective consumption is a function of $\omega_{t} l_{t}$. Moreover, production linearly depends on labor income $\left(y_{t}=\omega_{t} l_{t} /(1-s)\right)$.
} 


\subsubsection{A Numerical Illustration}

In order to further highlight the role of public spending externalities on the emergence of indeterminacy, we provide below a numerical exercise intended to assess the empirical plausibility of our analysis. We set $\theta=0.0123$, which corresponds to a monthly depreciation rate $(\delta)$ of 0.0083 and to a monthly $\beta=0.9956$. For the capital income share we use $s=0.4$. See Cooley and Prescott (1995). In what concerns the labor income tax rate, Mendoza et al. (1994) provide estimates that range from 0.23 to 0.285 for the United States and from 0.27 to 0.47 for a group of six other countries (UK, France, Germany, Italy, Canada and Japan). We will therefore consider two values for $\alpha_{l}$, respectively 0.24 and 0.43 , to represent the two polar cases of the United States versus Europe. As values for $\phi_{l}$ and $\eta$ are more difficult to pin-down we choose to consider an open interval for these two elasticities. For $\phi_{l}$ we will concentrate on values in the interval $(-2,2)$ that covers most of the existing situations, in particular the benchmark cases of a constant tax rate $\left(\phi_{l}=0\right)$ and of constant government expenditures $\left(\phi_{l}=-1\right)$. In the case of $\eta$ we will consider an interval consistent with the empirical values provided by $\mathrm{Ni}$ (1995). In his empirical study $\mathrm{Ni}$ (1995) validates a utility function of the non-separable Cobb-Douglas form $U\left(c_{t}, G_{t}\right)=U\left(c_{t}^{\theta_{1}} G_{t}^{\theta_{2}}\right)$ with $\theta_{1}, \theta_{2}>0$, that is equivalent to our formulation (see $\left.(7)\right)$ for $\eta=\theta_{2} / \theta_{1}$. Imposing $\theta_{1}+\theta_{2}=1$ he obtains values for $\theta_{1}$ between 0.64 and 0.75 , which imply values for $\eta$ between 0.33 and 0.56 . Note, however, that the condition $\theta_{1}+\theta_{2}=1$ he imposes may restrict significantly his empirical estimates. Nevertheless his results suggest that public expenditures are non-separable and complements to private consumption, and that the relative weight of private consumption in effective consumption is most probably higher than the one of government expenditures $\left(\theta_{1}>\theta_{2}\right)$. Therefore, in our numerical exercise, we will concentrate on values for $\eta$ between 0 and $1 .{ }^{18}$

We start now analyzing the case where $\alpha_{l}=0.24$, that corresponds to the case of the United States economy. In this case indeterminacy only

\footnotetext{
${ }^{18}$ Since we are considering fixed values for $\alpha_{l}$ we have to rewrite our indeterminacy conditions accordingly. Using Proposition 3 we can state that, for a fixed value of $0<$ $\alpha_{l}<1$, indeterminacy emerges for $\phi_{l}<-1$ iff $\eta<\eta^{H}$ or $\eta>\eta^{F}$, whereas for $\phi_{l}>-1$ we have indeterminacy iff $\eta>\eta^{H}$ or $\eta<\eta^{F}$, where $\eta^{H}=\frac{[s-\theta(1-s)]\left(1-\alpha_{l}\right)+\phi_{l} \alpha_{l}(1-s)}{(1-s)\left(1-\alpha_{l}\right)\left(1+\phi_{l}\right)}$ and $\eta^{F}=\frac{-2[2-s-\theta(1-s)]\left(1-\alpha_{l}\right)+\phi_{l} \alpha_{l}(1-s)(2-\theta)}{(2-\theta)(1-s)\left(1-\alpha_{l}\right)\left(1+\phi_{l}\right)}$. For $\phi_{l}=-1$, as we have seen, since $G$ is constant the effect of public spending externalities disappears, and indeterminacy simply requires $\alpha_{l}>\alpha_{l}^{*}(=0.396$ with our parameterization $)$.
} 
emerges for sufficiently high values of $\eta$ and $\phi_{l}$. Indeed, for any $\eta \in[0,1]$, indeterminacy does not appear when $-2<\phi_{l} \leq-0.5 .{ }^{19}$ For $-0.5<\phi_{l}<2$, indeterminacy requires a lower bound for $\eta$ decreasing in $\phi_{l}$. For example when $\phi_{l}=0$, the case of a constant tax rate, indeterminacy requires $\eta>$ $\eta^{*}=0.654$, whereas the lower limit for $\eta$ compatible with indeterminacy is 0.485 for $\phi_{l}=1$ and 0.428 for $\phi_{l}=2$.

We now consider the case where $\alpha_{l}=0.43$, that corresponds to the case of the European economy. Indeterminacy is now possible for any $\phi_{l}$ between -2 and 2 , becoming more likely as $\phi_{l}$ approaches -1 . Indeed, for $-1.4<\phi_{l} \leq$ -0.87 and all $\eta$ between 0 and 1 , indeterminacy is a pervasive phenomenon. ${ }^{20}$ For $-2<\phi_{l}<-1.4$ indeterminacy requires an upper bound for $\eta$, increasing with $\phi_{l}$ while for $-0.87<\phi_{l}<2$, indeterminacy only emerges above a lower bound for $\eta$ also increasing with $\phi_{l}$. Indeed, the lower limit for $\eta$ compatible with indeterminacy is 0 for $\phi_{l}=-0.87$, reaching 0.72 for $\phi_{l}=2$. As in the previous case, this lower limit is $\eta^{*}=0.654$ when $\phi_{l}=0$.

From this numerical exercise a few interesting conclusions emerge. In countries, like the United States, where the average labor income tax rate is sufficiently small (below $\alpha_{l}^{*}$ ), a tax rate schedule with an elasticity below or identical to -0.5 is capable of insulating the economy from belief driven fluctuations, for any value of $\eta$ empirically relevant. In contrast, when the tax-schedule elasticity is above -0.5 the likelihood of sunspots fluctuations, for empirically relevant values of public spending externalities, is increasing with $\phi_{l}$, so that, in order to eradicate belief driven fluctuations, tax rate elasticities should be sufficiently low. For example, if $\eta=0.5$ a $\phi_{l}$ below 0.8 is necessary to avoid sunspots, whereas for $\eta=\eta^{*}=0.654$ the tax rate elasticity is required to be negative. On the contrary, in countries, like France, Germany or Italy, with a high labor income tax rate (above $\alpha_{l}^{*}$ ), a tax rate schedule with an elasticity below or identical to -0.87 , leads to sunspots fluctuations for most empirically relevant values for $\eta$. Moreover, in these high labor income tax rate countries, when $\phi_{l}>-0.87$ the likelihood of sunspot fluctuations, for empirically relevant values of public spending externalities, is decreasing with $\phi_{l}$. Therefore in order to insulate the economy from belief driven fluctuations a sufficiently high $\phi_{l}$ is required. For example if $\eta=0.5$ a $\phi_{l}$ above $-0,6$ is necessary to avoid sunspots, whereas if $\eta=\eta^{*}=0.654$ a

\footnotetext{
${ }^{19}$ Note that, since in this case we have $\alpha_{l}<\alpha_{l}^{*}=0.396$, indeterminacy never emerges in the case of constant public expenditures $\left(\phi_{l}=-1\right)$.

${ }^{20}$ Note that in this case, as $\alpha_{l}>\alpha_{l}^{*}=0.396$, indeterminacy always emerges with constant public expenditures $\left(\phi_{l}=-1\right)$.
} 
positive tax rate elasticity is required.

From this numerical exercise we can confirm that public spending externalities, compatible with empirical estimates, matter for the emergence of indeterminacy and sunspots. Indeed, they affect significantly the combinations of $\phi_{l}$ and $\alpha_{l}$ capable of generating sunspot fluctuations, and therefore the effects of the policy rule.

\subsection{Indeterminacy with Consumption Taxes}

We consider now that the government only uses consumption taxes, i.e. that $\alpha_{l}=0$ so that $\tau_{l}\left(\omega_{t} l_{t}\right)=0$ (see $(5)$ ). To simplify the analysis, we ignore public spending externalities in preferences, i.e. $\eta=0$, so that $(22)$ becomes:

$$
\varphi\left(k_{t+1}, l_{t+1}\right)=\frac{1}{1+\tau_{c}\left(c_{t+1}\right)}
$$

where $\tau_{c}\left(c_{t}\right)$ is given by (6), and using $(2),(3),(17)$ and (19) $c_{t}$ satisfies the following equation:

$$
\begin{aligned}
\left(1+\tau_{c}\left(c_{t}\right)\right) c_{t} & =\omega_{t} l_{t}+(1-\beta) R_{t} k_{t} \\
& =k_{t}\left[(1-\beta)(1-\delta)+(1-s \beta) k_{t}^{s-1} l_{t}^{1-s}\right]
\end{aligned}
$$

Accordingly we have that

$$
\begin{aligned}
\varepsilon_{\varphi l} & =\frac{-\alpha_{c} \phi_{c}}{1+\alpha_{c}\left(1+\phi_{c}\right)}\left[\frac{(1-s)(1-\beta s) \theta}{(1-s) \theta+(1-\beta) s}\right] \\
\varepsilon_{\varphi k} & =\frac{-\alpha_{c} \phi_{c}}{1+\alpha_{c}\left(1+\phi_{c}\right)}\left[1-\frac{(1-s)(1-\beta s) \theta}{(1-s) \theta+(1-\beta) s}\right]
\end{aligned}
$$

so that $\epsilon_{\varphi}($ see $(23))$ is given by: $:^{21}$

$$
\epsilon_{\varphi}=\frac{-\alpha_{c} \phi_{c}}{1+\alpha_{c}\left(1+\phi_{c}\right)}
$$

As in the case of labor taxation $\epsilon_{\varphi}$ summarizes the variability of the distortion due to fiscal policy. Since $\eta=0, \epsilon_{\varphi}$ has only a term which represents the variability of the tax wedge.

\footnotetext{
${ }^{21}$ Note that here $\epsilon_{\varphi}$ represents also the elasticity of the function $\varphi$ with respect to income used for consumption expenditures, evaluated at the steady state. One can also easily determine the elasticity of the distortion with respect to the tax base, which is equal to $-\alpha_{c} \phi_{c} /\left(1+\alpha_{c}\right)$.
} 
Using Proposition 2 we now derive the indeterminacy conditions corresponding to the consumption taxation case that we summarize in Proposition 4 below. Again, in order to make the analysis comparable to the existing literature, we have set $\epsilon_{\gamma}=1$.

\section{Proposition 4 Indeterminacy under consumption taxation:}

Assuming that $\theta(1-s)<s$ and that $\epsilon_{\gamma}=1$, the steady state is indeterminate if and only if $\epsilon_{\varphi}>\nu$ or $\epsilon_{\varphi}<-\rho$, i.e. iff $\phi_{c}^{F}<\phi_{c}<\phi_{c}^{H}$ for $\phi_{c} \neq-\left(1+\alpha_{c}\right) / \alpha_{c}$ where..$^{22}$

$$
\begin{aligned}
\phi_{c}^{H} & =-\frac{v}{(1+v)} \frac{\left(1+\alpha_{c}\right)}{\alpha_{c}}<0 \\
\phi_{c}^{F} & =-\frac{\rho}{(\rho-1)} \frac{\left(1+\alpha_{c}\right)}{\alpha_{c}}<0 \\
\nu & =\frac{[s-\theta(1-s)][(1-s) \theta+(1-\beta) s]}{(1-s)(1-\beta s) \theta}>0 \\
\rho & =\frac{2[2-s-\theta(1-s)][(1-s) \theta+(1-\beta) s]}{\theta(1-s)[2-s-(1-s) \theta-\beta s]}>1
\end{aligned}
$$

Proof. See the Appendix.

From Proposition 4 we can immediately see that, as in the case of labor taxation, indeterminacy requires a sufficiently strong (in absolute value) variability of the function $\varphi$. Indeed, with both types of taxation the mechanisms operating are the same, so that both the requirements and the intuition for the emergence of indeterminacy are similar. Therefore, the economic intuition provided in the previous section also applies in this case. There remains however a difference worth emphasizing. In the case of labor taxation, and ignoring for the sake of simplicity public spending externalities, positive (negative) values for $\epsilon_{\varphi}$ are always associated with negative (positive) values for $\phi$, whereas in the case of consumption taxes this is no longer true. See equation (33). ${ }^{23}$ This explains why the indeterminacy results expressed in terms

\footnotetext{
${ }^{22}$ Note that for $\phi_{c}=-\left(1+\alpha_{c}\right) / \alpha_{c}$ steady state consumption is not well defined (see $(30))$.

${ }^{23}$ Indeed a positive $\epsilon_{\varphi}$ implies that $-\left(1+\alpha_{c}\right) / \alpha_{c}<\phi_{c}<0$, and a negative $\epsilon_{\varphi}$ means that either $\phi_{c}<-\left(1+\alpha_{c}\right) / \alpha_{c}$ or $\phi_{c}>0$. However, when $\phi_{c}>0, \epsilon_{\varphi}>-1$, so that $\epsilon_{\varphi}$ is never below $-\rho<-1$. Therefore indeterminacy never emerges when $\phi_{c}>0$. See figure 3 .
} 
of the tax rate and its variability are so different in the cases of labor and consumption taxes.

(insert figure 3 here)

In figure 3 we have represented the indeterminacy region (shaded area) in the plane $\left(\alpha_{c}, \phi_{c}\right)$, by plotting the functions $-\frac{1+\alpha_{c}}{\alpha_{c}}, \phi_{c}^{F}$, and $\phi_{c}^{H}$ as functions of $\alpha_{c}$ considering, as before, $s>\theta(1-s)$. We can see that indeterminacy with consumption taxes is only possible for $\phi_{c}<0$, so that a consumption tax rate that is increasing in the tax base implies local determinacy. Also, when the tax rate is constant $\left(\phi_{c}=0\right)$ the steady state is never locally indeterminate, as in the case of labor taxation without government spending externalities. ${ }^{24}$ In the context of a Ramsey model, Giannitsarou (2007) found that indeterminacy is not possible when a fixed stream of government spending is financed by consumption taxes. On the contrary, in our set up, indeterminacy is possible when government spending is constant. Indeed, this case is here recovered assuming that $\phi_{c}=-1$, and, from figure 3 , we can see that in this case, and as in the case of labor taxation, indeterminacy emerges when $\alpha_{c}$ is sufficiently high $\left(\alpha_{c}>\nu=0.808\right.$ with our parameterization).

The sharp difference between our results and those of Giannitsarou (2007) shows that the effects of policy rules on indeterminacy crucially depend on the financial market imperfections existing in the economy.

\section{Concluding Remarks}

In this paper we studied the role of public spending externalities and variable tax rates on local indeterminacy. As it is well-known, indeterminacy of equilibria is associated with the occurrence of fluctuations driven by self fulfilling prophecies (sunspots). Therefore, as it has already been stressed in the literature, fiscal policy rules that promote indeterminacy may have destabilizing effects on the economy. In this paper we contribute to this debate by showing that the destabilizing effects of different fiscal rules cannot be correctly assessed without taking into consideration the possible existence (and degree) of public spending externalities and/or the existence of financial markets imperfections. Indeed we have shown that the same policy rule can have

\footnotetext{
${ }^{24}$ Indeed when $\phi_{c}=0$ we have that $\varepsilon_{\varphi l}=\varepsilon_{\varphi k}=0$, so that indeterminacy does not emerge.
} 
completely different effects on stability depending on the strength of public spending externalities. Moreover, we have established that the presence of imperfect financial markets can clearly reverse the (de)stabilizing outcomes of some fiscal policy rules (see for instance our discussion on consumption taxes).

Finally, it can be shown that a Woodford economy with government spending financed by labor income and/or consumption taxation is isomorphic to an overlapping generations framework (without first period consumption as developed in Reichlin (1986)) with government spending financed by capital income and/or consumption taxes. Therefore, the indeterminacy mechanisms operating are the same, coming in both cases from the variability of the distortion introduced by government intervention. For a further discussion on this topic the reader is referred to a former version of this paper, Lloyd-Braga, Modesto and Seegmuller (2006). ${ }^{25}$

\section{Appendix}

\subsection{Proof of Proposition 1}

Studying the existence and uniqueness of the steady state $(k, l)$ of the dynamic system (20) and (21) is equivalent to analyze the existence and uniqueness of a stationary solution $(a, l)$, with $a \equiv k / l$, of the two following equations:

$$
\begin{aligned}
s a^{s-1} & =\theta / \beta \\
(1-s) a^{s} l \varphi(a l, l) / B & =\gamma(l)
\end{aligned}
$$

We can easily see that $a^{*}$ is the unique solution to equation (34). Since $H(l)$ is a continuous function, under the boundary assumptions on $B$ stated in Proposition 1, there exists a value $l^{*}$ solving (35) with $a=a^{*}$. Uniqueness of $l^{*}$ is ensured by inequalities 1 or 2 in Proposition 1 , because in these cases $H(l)$ is a monotonic function.

\footnotetext{
${ }^{25}$ This conclusion can be related to Dromel and Pintus (2004) who also remark that capital taxation in OLG models and labor taxation in the Woodford framework have similar effects for the occurrence of indeterminacy.
} 


\subsection{Proof of Proposition 2}

To study the local indeterminacy of the steady state, assuming that Proposition 1 is verified, we differentiate the two-dimensional dynamic system (20) and (21) in the neighborhood of the steady state. The trace $T$ and the determinant $D$ of the associated Jacobian matrix are given by:

$$
\begin{aligned}
T & =1+\frac{\varepsilon_{\gamma}-\theta(1-s)\left(1+\varepsilon_{\varphi l}+\varepsilon_{\varphi k}\right)}{\varepsilon_{\varphi l}+1-s} \\
D & =\frac{\varepsilon_{\gamma}[1-\theta(1-s)]}{\varepsilon_{\varphi l}+1-s}
\end{aligned}
$$

where $\varepsilon_{\gamma} \geq 1, \varepsilon_{\varphi k}$ and $\varepsilon_{\varphi l}$ denote respectively the elasticities $\varepsilon_{\gamma}(l), \varepsilon_{\varphi k}(k, l)$ and $\varepsilon_{\varphi l}(k, l)$ evaluated at the steady state. Since we only have one predetermined variable (capital) the steady-state is locally indeterminate when it is a sink (both eigenvalues, i.e. both roots of the characteristic polynomial $P(\lambda)=\lambda^{2}-\lambda T+D=0$, with modulus lower than one). Therefore indeterminacy requires that $D<1,1-T+D>0$ and $1+T+D>0$. When the denominator of both the trace and the determinant is positive $\left(\varepsilon_{\varphi l}>s-1\right)$ these conditions can be written respectively as $\varepsilon_{\varphi l}>\varepsilon_{\varphi l}^{H}, \varepsilon_{\varphi l}>\varepsilon_{\varphi l}^{T}$, and $\varepsilon_{\varphi l}>\varepsilon_{\varphi l}^{F}$ where $\varepsilon_{\varphi l}^{H}, \varepsilon_{\varphi l}^{T}$ and $\varepsilon_{\varphi l}^{F}$ are given in Proposition 2. When the denominator of both the trace and the determinant is negative $\left(\varepsilon_{\varphi l}<s-1\right)$ these conditions can be written respectively as $\varepsilon_{\varphi l}<\varepsilon_{\varphi l}^{H}$, $\varepsilon_{\varphi l}<\varepsilon_{\varphi l}^{T}$, and $\varepsilon_{\varphi l}<\varepsilon_{\varphi l}^{F}$. Combining these results, and noticing that $\varepsilon_{\varphi l}^{H}>s-1$, Proposition 2 immediately follows.

\subsection{Proof of Proposition 3}

We apply Proposition 2. Using expressions (26) to (28), it is easy to show that, for $\epsilon_{\gamma}=1$, conditions (i) and (ii) of Proposition 2 can be written as $\epsilon_{\varphi}>\max \left\{0, \frac{[s-\theta(1-s)]}{(1-s)}, \frac{-2[2-s-\theta(1-s)]}{(2-\theta)(1-s)}\right\}$ and $\epsilon_{\varphi}<\min \left\{-1,0, \frac{-2[2-s-\theta(1-s)]}{(2-\theta)(1-s)}\right\}$. Since, for $\theta(1-s)<s, \frac{[s-\theta(1-s)]}{(1-s)}=\max \left\{0, \frac{[s-\theta(1-s)]}{(1-s)}, \frac{-2[2-s-\theta(1-s)]}{(2-\theta)(1-s)}\right\}$ and $\frac{-2[2-s-\theta(1-s)]}{(2-\theta)(1-s)}=\min \left\{-1,0, \frac{-2[2-s-\theta(1-s)]}{(2-\theta)(1-s)}\right\}$, these two conditions become respectively $\epsilon_{\varphi}>\frac{[s-\theta(1-s)]}{(1-s)}$ and $\epsilon_{\varphi}<\frac{-2[2-s-\theta(1-s)]}{(2-\theta)(1-s)}$. Then, using expression (28) to substitute $\epsilon_{\varphi}$ in these two last inequalities, it is straightforward to obtain Proposition 3. 


\subsection{Proof of Proposition 4}

We apply Proposition 2. Using expressions (31) to (33), it is easy to show that, for $\epsilon_{\gamma}=1$, conditions (i) and (ii) of Proposition 2 become respectively $\epsilon_{\varphi}>\max \{0, \nu,-\rho\}$ and $\epsilon_{\varphi}<\min \left\{-\frac{[(1-s) \theta+(1-\beta) s]}{(1-\beta s) \theta}, 0,-\rho\right\}$. Since for $\theta(1-$ $s)<s \nu=\max \{0, \nu,-\rho\}$ and $-\rho=\min \left\{-\frac{[(1-s) \theta+(1-\beta) s]}{(1-\beta s) \theta}, 0,-\rho\right\}$, those conditions become respectively $\epsilon_{\varphi}>\nu$ and $\epsilon_{\varphi}<-\rho$. Then, substituting expression (33) in these last two inequalities, it is straightforward to obtain Proposition 4.

\section{References}

[1] Amano, R. and T. Wirjanto (1998), "Government Expenditures and the Permanent-Income Model", Review of Economic Dynamics, 1, 719-730.

[2] Barro, R. (1981), "Output Effects of Government Purchases", Journal of Political Economy, 89, 1086-1121.

[3] Benhabib, J. and R. Farmer (1994), "Indeterminacy and Increasing Returns", Journal of Economic Theory, 63, 19-41.

[4] Cazzavillan, G. (1996), "Public Spending, Endogenous Growth, and Endogenous Fluctuations", Journal of Economic Theory, 71, 394-415.

[5] Cazzavillan, G., T. Lloyd-Braga and P. Pintus (1998), "Multiple Steady States and Endogenous Fluctuations with Increasing Returns to Scale in Production", Journal of Economic Theory, 80, 60-107.

[6] Christiano, L. and S. G. Harrison (1999), "Chaos, Sunspots and Automatic Stabilizers", Journal of Monetary Economics, 44, 3-31.

[7] Cooley, T.F. and E.C. Prescott, (1995), "Economic Growth and Business Cycles", in Frontiers of Business Cycle Research, (T.F. Cooley, Ed.), Princeton University Press, Princeton, ch. 1, 1-38.

[8] Dromel, N. and P. Pintus (2004), "Progressive Income Taxes as Built-in Stabilizers", Working Paper GREQAM, Aix-Marseille. 
[9] Evans, P. and G. Karras (1996), "Private and Government Consumption with Liquidity Constraints", Journal of International Money and Finance, 15, 255-266.

[10] Fernandez, E., A. Novales and J. Ruiz (2004), "Indeterminacy under Non-Separability of Public Consumption and Leisure in the Utility Function", Economic Modelling, 21, 409-428.

[11] Giannitsarou, C. (2007), "Balanced Budget Rules and Aggregate Instability: The Role of Consumption Taxes", forthcoming in Economic Journal.

[12] Gokan, Y. (2006), "Dynamic Effects of Government Expenditure in a Finance Constrained Economy", Journal of Economic Theory, 127, 323333.

[13] Grandmont, J. M., P. Pintus and R. de Vilder (1998), "Capital-Labor Substitution and Competitive Nonlinear Endogenous Business Cycles", Journal of Economic Theory, 80, 14-59.

[14] Guo, J. T. and S. G. Harrison (2004), "Balanced-Budget Rules and Macroeconomic (In)stability", Journal of Economic Theory, 119, 357363.

[15] Guo, J. T. and S. G. Harrison (2006), "Useful Government Spending and Macroeconomic (In)stability under Balanced-Budget Rules", Working Paper, University of California.

[16] Guo, J.T. and K. Lansing (1998), "Indeterminacy and Stabilization Policy", Journal of Economic Theory, 82, 481-490.

[17] Karras, G. (1994), "Government Spending and Private Consumption: Some International Evidence", Journal of Money, Credit and Banking, $26,9-22$.

[18] Lloyd-Braga, T., L. Modesto and T. Seegmuller (2006), "Tax Rate Variability and Public Spending as Sources of Indeterminacy", CEPR, DP5796, http://www.cepr.org/pubs/dps/DP5796.asp.

[19] Mendoza, E.G., A. Razin and L. Tesar (1994), "Effective Tax Rates in Macroeconomics: Cross-Country Estimates of Tax Rates on Factor 
Incomes and Consumption", Journal of Monetary Economics, 34, 297323.

[20] Ni, S. (1995), "An Empirical Analysis on the Substitutability between Private Consumption and Government Purchases", Journal of Monetary Economics, 36, 593-605.

[21] Pintus, P. (2003), "Aggregate Instability in the Fixed-Cost Approach to Public Spending", mimeo, Aix-Marseille.

[22] Reichlin, P. (1986), "Equilibrium Cycles in an Overlapping Generations Economy with Production", Journal of Economic Theory, 40, 89-102.

[23] Schmitt-Grohé, S. and M. Uribe (1997), "Balanced- Budget Rules, Distortionary Taxes, and Aggregate Instability", Journal of Political Economy, 105, 976-1000.

[24] Seegmuller, T. (2003), "Endogenous Fluctuations and Public Services in a Simple OLG economy", Economics Bulletin, Vol. 5, No. 10, 1-7.

[25] Utaka, A. (2003), "Income Tax and Endogenous Business Cycles", Journal of Public Economic Theory, 5, 135-145.

[26] Woodford, M. (1986), "Stationary Sunspot Equilibria in a Finance Constrained Economy", Journal of Economic Theory, 40, 128-137.

[27] Zhang, J. (2000), "Public Services, Increasing Returns, and Equilibrium Dynamics", Journal of Economic Dynamics and Control, 24, 227-246. 


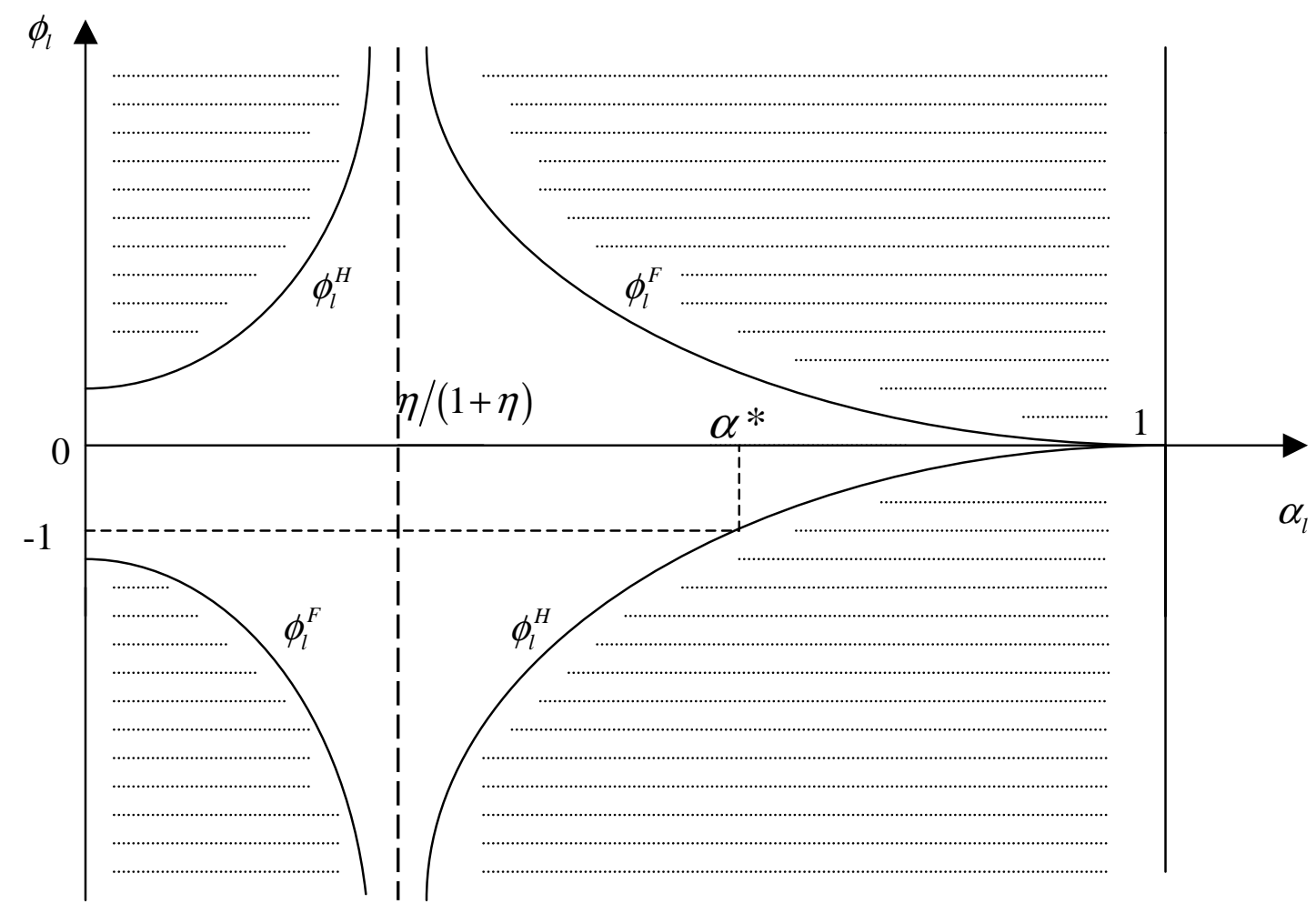

Figure 1

Indeterminacy with labor income taxation: $0 \leq \eta<\eta^{*}$ 


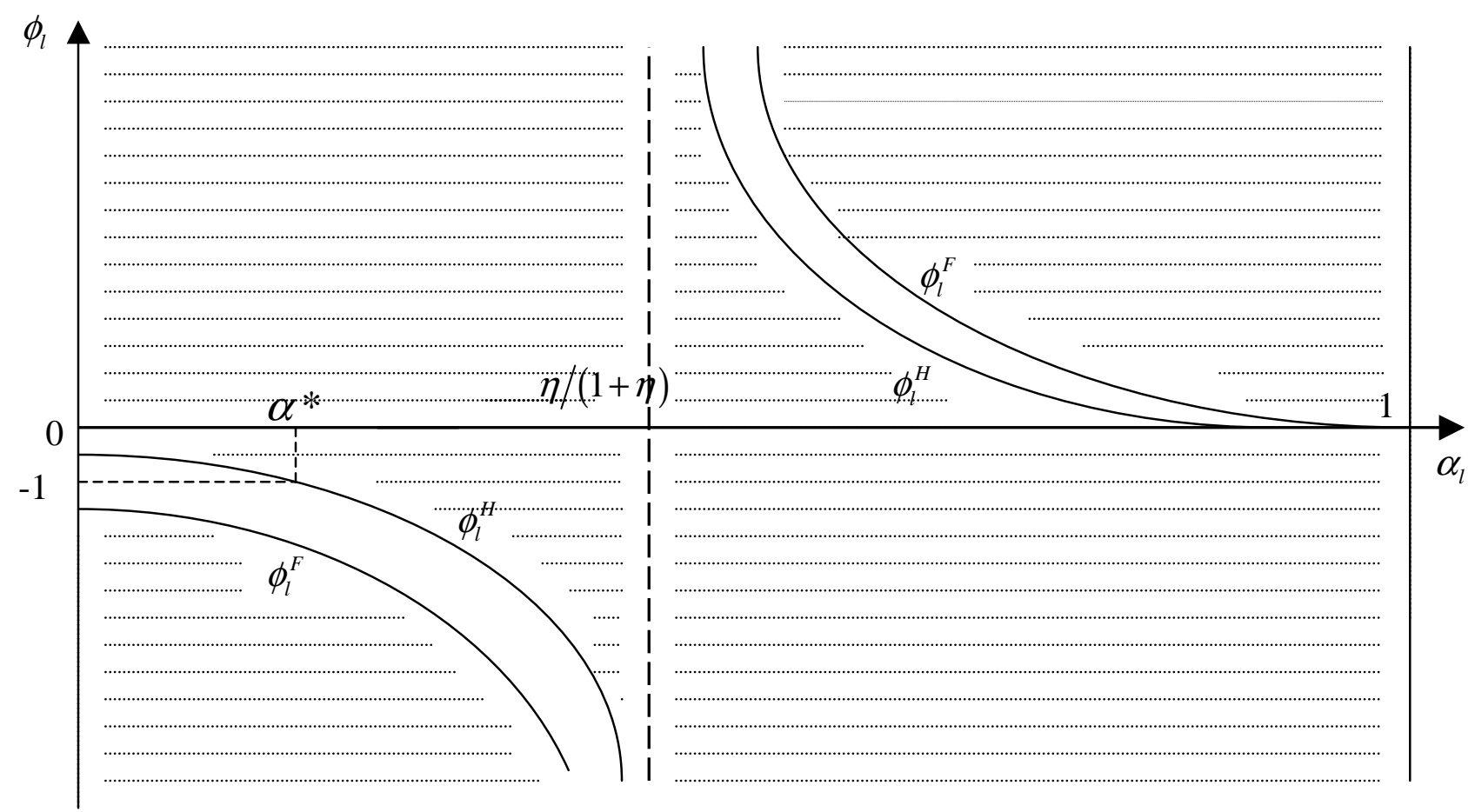

Figure 2

Indeterminacy with labor income taxation: $\eta>\eta^{*}$ 


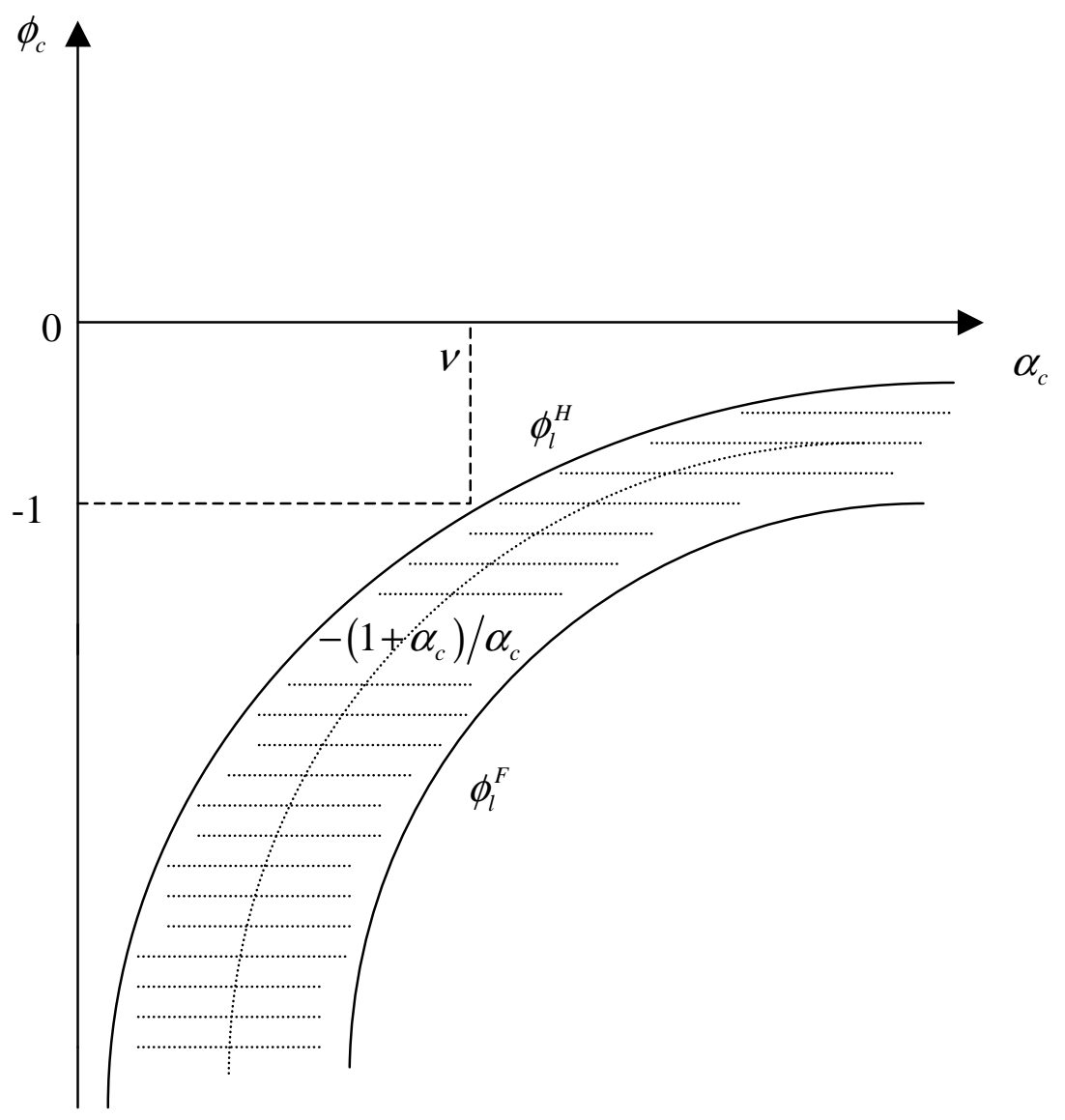

Figure 3

Indeterminacy with consumption taxation: $\eta=0$ 